Psychother Psychosom 2020;89:51-53

DOI: 10.1159/000503116

\section{Cognitive-Behavioral Therapy for Adolescents with an Age-Adapted Diagnosis of Binge-Eating Disorder: A Randomized Clinical Trial}

\author{
Anja Hilbert ${ }^{\mathrm{a}, \mathrm{b}}$ David Petroffa, c Petra Neuhaus ${ }^{\mathrm{a}, \mathrm{c}}$ \\ Ricarda Schmidt ${ }^{\mathrm{a}, \mathrm{b}}$ \\ a Integrated Research and Treatment Center Adiposity \\ Diseases, Leipzig University Medical Center, Leipzig, Germany; \\ ${ }^{b}$ Department of Medical Psychology and Medical Sociology, \\ Department of Psychosomatic Medicine and Psychotherapy, \\ Leipzig University Medical Center, Leipzig, Germany; ${ }^{\mathrm{C} C l i n i c a l}$ \\ Trial Centre Leipzig, University of Leipzig, Leipzig, Germany
}

Binge-eating disorder (BED) is characterized by recurrent objective binge eating that occurs in the absence of compensatory behaviors to prevent weight gain. As the most common eating disorder emerging in youth, BED co-occurs with increased eating disorder and general psychopathology, impaired quality of life, and obesity [1]. Despite its clinical significance, there is a dearth of treatment studies in adolescents $[1,2]$. Regarding cognitive-behavioral therapy (CBT), the most well-established treatment for adults with BED [2], one pilot randomized-controlled trial (RCT) in 25 adolescent girls with objective binge eating suggested superiority to wait-list (WL) in achieving binge-eating abstinence through 6 months following randomization and in improving eating disorder psychopathology, but not in reducing binge eating or standardized body mass index (BMI; kg/m²) [3]. Other CBT-related RCTs documented efficacy of Internet-based, weight loss-oriented self-help versus WL [4] and no differences in dialectical behavior therapy versus weight management [5]. Based on this preliminary evidence, the aim of the BEDA (Binge Eating Disorder in Adolescents) study was to provide a confirmatory test of the efficacy of $\mathrm{CBT}$ in adolescent BED. It was hypothesized that CBT will be superior to WL in improving binge eating, associated psychopathology, and quality of life, but not BMI, with long-term maintenance of effects.

Methodological details of the BEDA study can be found in Hilbert [6] and online supplementary materials (for all online suppl. material, see www.karger.com/doi/10.1159/000503116). The study, registered and ethically approved, was conducted at Leipzig University Medical Center. Recruitment took place mainly through population- and school-based advertising. Inclusion required age 12-20 years; informed written consent (and assent); and ageadapted diagnosis of BED (DSM-IV-TR, DSM-5) or BED of low frequency and/or limited duration (DSM-5), all based on binge eating (i.e., objective and/or subjective binge eating). Patients were assessed at baseline, 4 months after randomization (post-assessment), and at 6-, 12-, and 24-month follow-up after treatment. The WL group was additionally assessed after delayed CBT. Ageadapted CBT, derived from an evidence-based [7] manual for adults with BED [6], was conducted in twenty 50-min individual sessions with the adolescent over 4 months.

Of 340 adolescents screened for eligibility, 102 were scheduled for an in-person assessment to determine inclusion. Of these, 73 adolescents $(15.3 \pm 2.5$ years, $82 \%$ girls $)$ were randomized to CBT $(n=37)$ or WL $(n=36)$ (online suppl. Fig. S1; online suppl. Tables $\mathrm{S} 1, \mathrm{~S} 2)$. Treatment drop-out (<10 CBT sessions attended) was $32 \%$ (9/37 in the CBT arm, 14/36 in the WL arm). Safety of CBT was established (online suppl. Table S3).

Regarding the primary outcome of binge-eating episodes (Eating Disorder Examination), intent-to-treat (ITT) analyses revealed 4.7 ( $p=0.0066)$ fewer monthly binge-eating episodes at post-assessment in the CBT versus WL group (Table 1; online suppl. Figs. S2, S3). Regarding secondary outcomes, the CBT group achieved higher rates of abstinence from binge eating (51 vs. 33\%) and remission from BED (57 vs. $33 \%$ ) and a lower eating disorder psychopathology at post-assessment (all $p<0.05$ ), while the groups did not differ in depression, self-esteem, quality of life, and standardized BMI (all $p>0.05)$. Longitudinal ITT analyses showed that after CBT, binge-eating episodes remained significantly reduced at $6-, 12-$, and 24-month follow-up when compared with baseline $(p<0.001$; online suppl. Tables S4, S5). Abstinence from binge eating remained stable at about $50 \%$, and remission from $B E D$ ranged from 59 to $70 \%$ across follow-up. For eating disorder psychopathology, depressive symptoms, self-esteem, and quality of life, significant improvements relative to baseline were revealed at all follow-up time points (all $p<0.001$ ), whereas standardized BMI was not significantly changed $(p>0.05)$. Sensitivity analyses confirmed these results (online suppl. Tables S6-S8).

This confirmatory RCT uniquely established the efficacy of individual CBT versus WL in improving binge-eating symptomatology and demonstrated long-term maintenance of effects over 24 months in adolescents with an age-adapted diagnosis of BED. The magnitude of the CBT versus WL effect is consistent with that in adolescent binge eaters [3], but lower than that in adult BED [2]. Adolescents started from lower baseline numbers of objective binge-eating episodes but reached subclinical post-treatment and follow-up numbers ( $\leq 2$ binge-eating episodes or $\leq 1$ objective binge-eating episode per month), comparable to those in adults with BED [7]. The significant effects of CBT versus WL on bingeeating abstinence and eating disorder psychopathology were consistent with previous evidence $[2,3]$ and were maintained through long-term follow-up. In contrast, significant improvements in depression, self-esteem, and quality of life were not specific to CBT, similar to evidence on adolescent binge eaters [3], but effects were smaller than those in CBT for adult BED, at least for depression

\section{KARGER}

(C) 2019 S. Karger AG, Basel

E-Mail karger@karger.com

www.karger.com/pps
Anja Hilbert

Integrated Research and Treatment Center AdiposityDiseases

Leipzig University Medical Center, Philipp-Rosenthal-Strasse 27

DE-04103 Leipzig (Germany)

E-Mail anja.hilbert@medizin.uni-leipzig.de 
Table 1. Intent-to-treat analyses for the primary and secondary outcomes

\begin{tabular}{|c|c|c|c|c|c|c|c|c|c|c|c|c|}
\hline & \multicolumn{4}{|c|}{ Baseline } & \multicolumn{4}{|c|}{ Post-assessment } & \multirow{3}{*}{$\begin{array}{l}\text { Adjusted } \\
\text { effect }\end{array}$} & \multirow{3}{*}{$95 \% \mathrm{CI}$} & \multirow{3}{*}{$\begin{array}{l}\text { Effect } \\
\text { size }\end{array}$} & \multirow[t]{3}{*}{$p$} \\
\hline & \multicolumn{2}{|c|}{$\begin{array}{l}\text { CBT } \\
(n=37)\end{array}$} & \multicolumn{2}{|c|}{$\begin{array}{l}\text { control } \\
(n=36)\end{array}$} & \multicolumn{2}{|c|}{$\begin{array}{l}\text { CBT } \\
(n=37)\end{array}$} & \multicolumn{2}{|c|}{$\begin{array}{l}\text { control } \\
(n=36)\end{array}$} & & & & \\
\hline & $\begin{array}{l}\text { mean } \\
\text { or } n\end{array}$ & $\begin{array}{l}\text { SD } \\
\text { or } \%\end{array}$ & $\begin{array}{l}\text { mean } \\
\text { or } n\end{array}$ & $\begin{array}{l}\text { SD } \\
\text { or } \%\end{array}$ & $\begin{array}{l}\text { mean } \\
\text { or } n\end{array}$ & $\begin{array}{l}\text { SD } \\
\text { or \% }\end{array}$ & $\begin{array}{l}\text { mean } \\
\text { or } n\end{array}$ & $\begin{array}{l}\text { SD } \\
\text { or } \%\end{array}$ & & & & \\
\hline \multicolumn{13}{|l|}{ Eating Disorder Examination } \\
\hline Binge-eating episodes & 11.8 & 9.8 & 11.2 & 8.9 & 1.3 & 3.1 & 6.0 & 8.6 & 4.7 & $1.6-7.9$ & 0.35 & 0.0038 \\
\hline Objective binge-eating episodes & 7.9 & 9.6 & 7.4 & 7.4 & 0.5 & 1.7 & 3.6 & 5.2 & 3.1 & $1.3-4.9$ & 0.38 & $<0.001$ \\
\hline Abstinence from binge eating & - & & - & & 19 & 51 & 12 & 33 & 3.0 & $1.0-9.8$ & 0.61 & 0.048 \\
\hline Remission from BED & - & & - & & 21 & 57 & 12 & 33 & 3.4 & $1.2-10.4$ & 0.67 & 0.022 \\
\hline Global eating disorder psychopathology & 2.3 & 0.9 & 2.2 & 0.8 & 1.4 & 0.9 & 2.0 & 0.9 & 0.7 & $0.2-1.2$ & 0.34 & 0.012 \\
\hline Beck Depression Inventory-II & 14.3 & 11.1 & 15.6 & 10.1 & 12.2 & 14.0 & 11.9 & 10.9 & -1.2 & $-7.5-5.1$ & -0.05 & 0.69 \\
\hline Rosenberg Self-Esteem Scale & 28.1 & 7.0 & 27.1 & 5.6 & 28.9 & 9.3 & 27.9 & 8.3 & 0.2 & $-4.2-4.7$ & 0.02 & 0.91 \\
\hline SF-12 Mental Quality of Life & 44.4 & 13.8 & 42.6 & 14.2 & 45.9 & 15.7 & 42.6 & 15.3 & 2.4 & $-6.6-11.3$ & 0.08 & 0.59 \\
\hline Body mass index SD score & 1.9 & 0.8 & 1.9 & 1.1 & 2.0 & 1.0 & 2.1 & 1.0 & 0.1 & $-0.3-0.6$ & 0.07 & 0.54 \\
\hline
\end{tabular}

For metric outcomes, positive values of the adjusted effect and effect size $d$ indicate superiority of CBT. For categorical outcomes, the odds ratio $>1.0$, used as effect size, indicates superiority of CBT. BED, binge-eating disorder; CBT, cognitive-behavioral therapy; SF-12, short-form health survey.

[2]. Given adolescents' low baseline level of impairment in these general indicators, a differential improvement may have been unlikely to be achieved. Notwithstanding, these improvements were sustained across follow-up. As in adolescent binge eaters [3] and adult BED [2], standardized BMI did not differ after CBT versus WL and was stabilized over long-term follow-up. Thus, the treatment of binge eating may foster normative growth and prevent excess weight gain, whereas adolescent BED predicted obesity in adulthood [8].

Strengths and limitations of this study include the use of a wellcontrolled design with low risk of selection and detection bias. As in other psychotherapy trials, blinding of patients and therapists was not possible, contributing to a performance bias. For preventing an attrition bias given the differential loss in CBT versus WL at post-assessment, analyses were conducted by ITT, with sensitivity analyses underscoring the robustness of the results. To avoid a reporting bias, methods had been published previously [6]. To ensure generalizability, exclusion criteria were kept to a minimum. Nevertheless, male patients were underrepresented, and corresponding to the population in the Leipzig region, most adolescents had German nationality, limiting the generalizability to more diverse populations.

Confirming the short-term efficacy of CBT and long-term maintenance of gains, the results support CBT as an evidencebased treatment of adolescent BED, which is essential for its establishment in healthcare systems. Future trials may determine the long-term efficacy of CBT beyond the tendency of BED for spontaneous remission and recurrence [9]; its comparative efficacy, for example, regarding interpersonal psychotherapy [10]; the optimal degree of family involvement given that our approach was adolescent focused; adjunctive interventions to foster weight loss in adolescents with BED and obesity; and the cost-effectiveness of CBT.

\section{Acknowledgements}

The authors are grateful to: Rebekka Kittel, PhD, Anne Pötzsch, $\mathrm{PhD}$, Cordula Aas, MSc, Maria Berger, MSc, Helen Eisner, MSc, Anja Kürzdörfer, MSc, Lisa Miebach, MSc, Charlotte Schmidt,
MSc, Nora Schlüter, MD, and Nino Shanidze, MSc, for their support in the conduct of this study; Nicole Köppe-Bauernfeind, MSc, Heidi Kulas, MSc, Stefanie Lehmann, and Evelyn Trips, MSc, from the Clinical Trial Centre of the University of Leipzig for their support in seeking ethical approval, study registration, preparation of the case report forms, randomization, data management, reports, and monitoring; the independent Data Monitoring and Safety Committee: Martina de Zwaan, MD (Hannover), Winfried Rief, $\mathrm{PhD}$ (Marburg), and Anja Broda, PhD (Leipzig); Jamie L. Manwaring, $\mathrm{PhD}$, and Frederike Obereigner for their help in editing this paper; and to our patients and their families for participation.

\section{Statement of Ethics}

Ethical approval was granted by the Ethics Committee of Leipzig University (235-10-23082010). Informed written assent and consent were obtained from all adolescents and at least 1 parent (for adolescents aged $<18$ years), respectively.

\section{Disclosure Statement}

Dr. Hilbert received royalties for books on CBT of BED and obesity with Hogrefe; honoraria for workshops and lectures on the psychosocial aspects and treatment of BED and obesity; honoraria as editor of the journal Psychotherapeut; honoraria as a reviewer from Mercator Research Center Ruhr, Western Sydney University, and Oxford University Press; funds for tangible means from the Danone Foundation; and honoraria as a consultant for WeightWatchers, Pope Woodhead, GlobalData, Informa Healthcare, and Simon-Kucher and Partners. Drs. Petroff, Neuhaus, and Schmidt have no conflicts of interest to declare.

\section{Funding Sources}

This research was supported by the German Federal Ministry of Education and Research (grant 01EO1501). The funding source had no role in the design and conduct of the study; collection, management, analysis, and interpretation of the data; preparation, review, or approval of the manuscript; and the decision to submit the manuscript for publication. 


\section{Author Contributions}

Drs. Hilbert and Petroff had full access to all data in the study and take responsibility for the integrity of the data and the accuracy of data analysis. Study concept and design; obtained funding; study supervision: Dr. Hilbert. Acquisition, analysis, interpretation of data; drafting of the manuscript, critical revision of the manuscript for important intellectual content; administrative, technical, or material support: Drs. Hilbert, Petroff, Neuhaus, and Schmidt. Data analysis: Drs. Petroff, Hilbert, and Schmidt.

\section{References}

1 Marzilli E, Cerniglia L, Cimino S. A narrative review of binge eating disorder in adolescence: prevalence, impact, and psychological treatment strategies. Adolesc Health Med Ther. 2018 Jan;9:17-30.

2 Hilbert A, Petroff D, Herpertz S, Pietrowsky R, Tuschen-Caffier B, Vocks $\mathrm{S}$, et al. Meta-analysis of the efficacy of psychological and medical treatments for binge-eating disorder. J Consult Clin Psychol. 2019 Jan;87(1): 91-105.

3 DeBar LL, Wilson GT, Yarborough BJ, Burns B, Oyler B, Hildebrandt T, et al. Cognitive behavioral treatment for recurrent binge eating in adolescent girls: A pilot trial. Cognit Behav Pract. 2013 May;20(2):147-61.

4 Jones M, Luce KH, Osborne MI, Taylor K, Cunning D, Doyle AC, et al. Randomized, controlled trial of an internet-facilitated intervention for reducing binge eating and overweight in adolescents. Pediatrics. 2008 Mar;121(3):453-62.
5 Mazzeo SE, Lydecker J, Harney M, Palmberg AA, Kelly NR, Gow RW, et al. Development and preliminary effectiveness of an innovative treatment for binge eating in racially diverse adolescent girls. Eat Behav. 2016 Aug;22:199-205.

6 Hilbert A. Cognitive-behavioral therapy for binge eating disorder in adolescents: study protocol for a randomized controlled trial. Trials. 2013 Sep;14(1):312.

7 de Zwaan M, Herpertz S, Zipfel S, Svaldi J, Friederich HC, Schmidt F, et al. Effect of Internet-based guided self-help vs individual face-to-face treatment on full or subsyndromal binge eating disorder in overweight or obese patients: the INTERBED randomized clinical trial. JAMA Psychiatry. 2017 Oct;74(10):987-95.

8 Micali N, Solmi F, Horton NJ, Crosby RD, Eddy KT, Calzo JP, et al. Adolescent eating disorders predict psychiatric, high-risk behaviors and weight outcomes in young adulthood. J Am Acad Child Adolesc Psychiatry. 2015 Aug;54(8):652-659.e1.

9 Stice E, Marti CN, Rohde P. Prevalence, incidence, impairment, and course of the proposed DSM-5 eating disorder diagnoses in an 8-year prospective community study of young women. J Abnorm Psychol. 2013 May;122(2):445-57.

10 Tanofsky-Kraff M, Shomaker LB, Wilfley DE, Young JF, Sbrocco T, Stephens $\mathrm{M}$, et al. Excess weight gain prevention in adolescents: three-year outcome following a randomized controlled trial. J Consult Clin Psychol. 2017 Mar;85(3):218-27. 